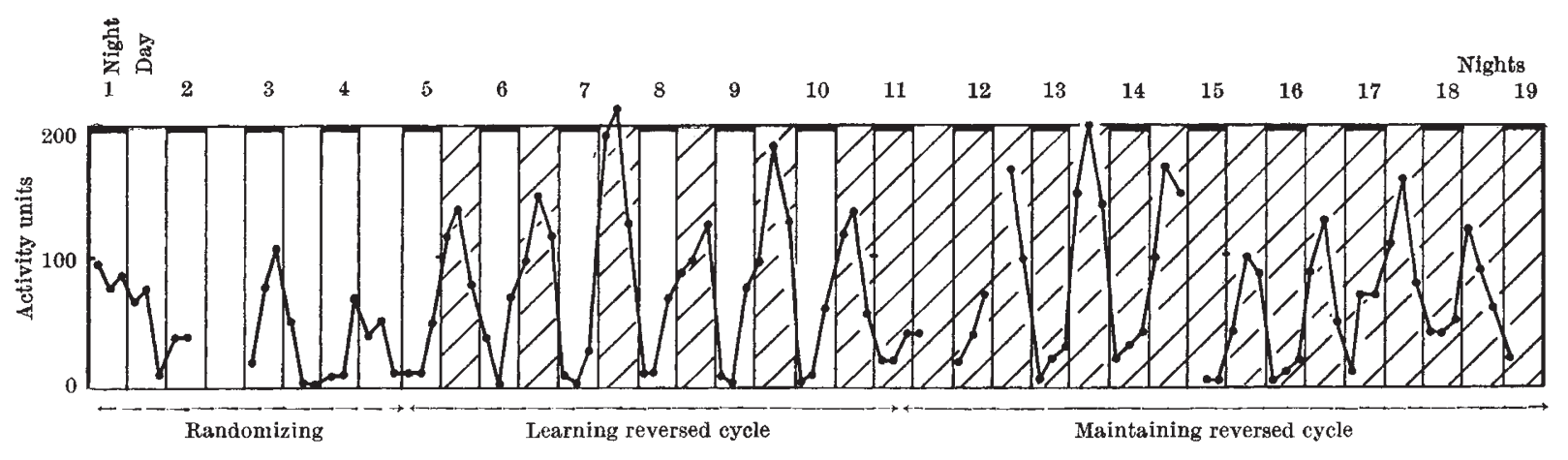

Fig. 1. Activity record. Darkness, shaded; light, plain

a similar periodicity, it is not influenced by the lighting conditions: it should be noticed that Henkes's experiments were of short duration. A discussion of the matter was given by $\mathrm{Park}^{3}$, who found some cases of applied periodicity and others where a 'deep-seated physiological rhythm' was involved.

Talorchestia, which burrows in the supra-littoral fringe of New Zealand sand beaches, remains below ground by day and forages on the shore at night. As one of us was engaged in a biological examination of the species ${ }^{4}$ it was decided to investigate the status of its daily rhythm. An 'Aktograph' device was employed with the temperature regulated to $12 \pm 1^{\circ} \mathrm{C}$. and a relative humidity of 100 per cent : algal food was provided in excess throughout the experiment. The animals burrowed in a radially partitioned annulus of damp sand which surrounded a silk platform sensitive to the weight of a single specimen. Activity was recorded on a drum, and was expressed on the basis of displacement counts per unit time: electric lighting was controlled by a time switch.

In a preliminary experiment with natural lighting it was established that there is nocturnal activity which reaches its peak at midnight, and fades to almost no activity by day.

A fresh collection of animals was placed in the instrument, and after an initial week of continuous preparatory illumination, was subjected to various lighting conditions over a period of eighteen days. The recordings were divided into three phases.

For the first four days tho lighting remained constant, so that the extent to which the activity had been randomized throughout the 24-hr. period could be assessed. It will be noticed (Figs. 1, 2) that, although some irregular periodicity remained, a large measure of disruption had been obtained.

Following this randomizing phase a reversed cycle of lighting was applied for six days : the animals were

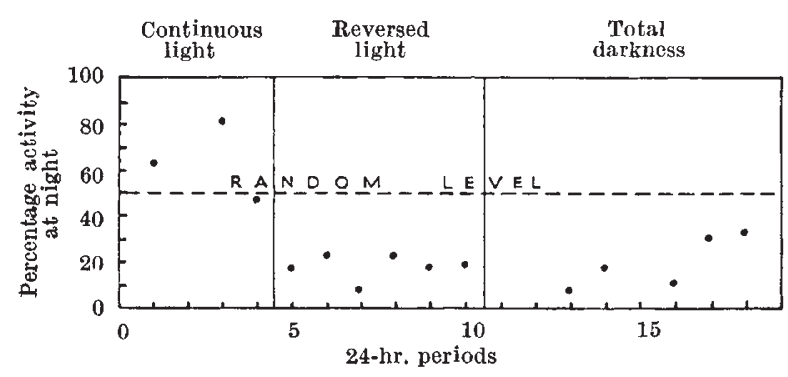

Fig. 2. Activity analysis. Note: Four values are omitted due to recording breaks subjected to light at night and darkness by day in an effort to produce a reversal of activity. Here there was an almost immediate change to very low night activity and high day activity.

In the final phase continuous darkness was applied for eight days to see if this artificial activity would be maintained. From the figures it can be seen that the reversed cycle was maintained with a drift towards the random level at the end of the period.

It is suggested that here the presence of light is the factor which governs activity, and hence gives rise to the periodicity in Nature, but that this is stabilized by a 'memory' factor of at least one week's duration, as was shown by the reversed cycle, learned in the second period, and maintained in the absence of stimuli.

Zoology Department, D. W. Featherston* R. J. MacIntyret

Canterbury University College, Christchurch, New Zealand.

* Present address: Nelson College, Nelson, New Zealand.

$\uparrow$ Present address : C.S.I.R.o. Division of Fisheries and Oceanography, Cronulla, New South Wales, Australia.

1 Cloudsley-Thompson, J. L., J. Exp, Biol., 28, 165 (1951); 29, 295 (1952).

2 Henkes, H. F., J, Exp. Biol. 29,178 (1952)

3 Park, O., Ecol. Monogr., 10, 485 (1940).

${ }^{4}$ MacIntyre, R. J.. M.Sc. thesis in zoology, Canterbury University College, New Zealand (1954).

\section{Salmonella vejle and S. saint paul}

WrTH reference to a communication in Nature of September 29, 1956, p. 702, we agree that the occurrence of Salmonella vejle and S. saint paul has apparently not been previously reported from South Africa. However, hitherto unpublished material from the South African Institute for Medical Research shows that both these organisms have been isolated from human sources in South Africa on several occasions in the past.

Approximately two thousand salmonellas have been investigated at the Salmonella Identification Unit of this Institute in the past three years. Five of these have been classified as $S$. vejle and nine as $S$. saint paul, both types appearing for the first time in February 1955.

\section{SCHRIRE \\ V. BOKKENHEUSER}

South African Institute for Medical Research, Johannesburg. 